Although the occurrence of such a tumour has been reported in association with ulcerative colitis, ${ }^{1}$ no such colonic tumour has been reported in association with Crohn's disease. In this case a composite carcinoma carcinoid tumour was found in the caecum affected by active Crohn's disease, and a focus of dysplasia and villous adenomatous change was seen in adjacent mucosa as well as in mucosa further away from the tumour (fig 3).

The occurrence of composite carcinoma carcinoid tumour in the colon can be readily explained by the tumour arising from the multipotent stem cells showing bidirectional differentiation, ${ }^{7}$ and the presence of a tubulovillous adenoma showing progressive dysplasia, finally becoming an infiltrating tumour in our case, is entirely in agreement with this view. However, why the tumour differentiated bidirectionally as such and whether Crohn's disease played any particu- lar role is not known.

We are grateful to Drs MG Freeth and C Allen for helpfu comments, Dr SY Chan for help with photomicrographs, and Mrs Sue Clarke for typing the manuscript.

1 Lyss AP, Thompson JJ, Glick JH. Adenocarcinoid tumour of the colon arising in pre-existing ulcerative colitis. Cancer 1981;48:833-9.

2 Saroca PE, Ballantyne GA, Cahow CE. Gastrointestina malignancies in Crohn's disease, a 20 year experience. Dis Colon Rectum 1990;33:7-11.

3 Gledhill A, Hall PA, Cruse JP, Pollock DJ Enteroendocrine cell hyperplasia, carcinoid tumours and adenocarcinoma in long-standing ulcerative colitis. Histopathology 1986; 10:501-8.

4 Hamilton SR. Colorectal carcinoma in patients with Crohn's disease. Gastroenterology 1985; 89:398-407.

5 Thompson EM, Clayden G, Price AB. Cancer in Crohn's disease- an 'occult' malignancy. Histopathology 1983; 7:365-76.

6 Craft CF, Mendelsohn G, Cooper HS, Yardley JH. Colonic 'precancer' in Crohn's disease. Gastroenterology 1981; 80:578-84.

7 Klappenbach RS, Kurman RJ, Sinclair CF, James LP. Composite carcinoma/carcinoid tumours of the gastrointestinal tract. Am f Clin Pathol 1985; 84:137-43.

\title{
Epithelial myoepithelial tumour of the tracheal gland
}

\author{
H Horinouchi, T Ishihara, M Kawamura, R Kato, K Kikuchi, K Kobayashi, Y Maenaka, \\ C Torikata
}

\begin{abstract}
A case of epithelial myoepithelial tumour originating from the tracheal gland in a 57 year old woman is described. The tumour was removed by segmental tracheal resection and end-to-end anastomosis. Histologically, the tumour comprised clear cells and presented a monophasic pattern. Immunohistochemical analysis showed that the tumour cells were positive for both S-100 protein and smooth muscle actin, suggesting that this tumour resembles a subtype of epithelial-myoepithelial carcinoma described in the 1990 WHO international classification of salivary glands.

Although some reports describe a clear cell dominant epithelial myoepithelial carcinoma, in this case local invasiveness or regional lymphnode metastasis was not proved through investigation. It is therefore concluded that this was an epithelial myoepithelial tumour rather than a carcinoma.
\end{abstract}

( $¥$ Clin Pathol 1993;46:185-187)

Among the cases difficult to classify histologically, the rare case presented here, that of a tracheal tumour, is thought to be a clear cell dominant epithelial myoepithelial tumour.
In 1972 Donath and coworkers reported a special form of a clear cell tumour of the salivary gland, which they termed epithelial myoepithelial carcinoma of the intercalated ducts. ${ }^{1}$ This type of tumour had been previously described as clear cell monomorphic adenoma in the WHO classification ${ }^{2}$ and the AFIP Tumor Fascicle. ${ }^{3}$

\section{Case Report}

A 57 year old Japanese woman was admitted in August 1988 because she was producing bloody sputum. She had been treated for bronchiectasis and diabetes mellitus by her family doctor since November 1985. A harsh, stenotic sound was audible on her neck. There was no cervical lymphadenopathy. The chest $X$ ray film revealed a large intraluminal defect in the cervical trachea (fig 1). A computed tomogram of the trachea indicated a clearly demarcated mass in the mid-trachea. Bronchofibroscopy showed the presence of polypoid tumour growing from the right side of the tracheal wall.

Surgery was performed in August 1988. The trachea was mobilised from the neck to the carina, sleeve resection comprising five tracheal rings (third to seventh tracheal cartilages) was performed, and an end-to-end anastomosis was accomplished. Additional regional lymph node dissection was done. A tiny, hard thyroid nodule in the right lower pole of the thyroid was found. This was also
Hon-komagome,

Bunkyou-ku, Tokyo 113, Japan

Accepted for publication 9 September 1992 


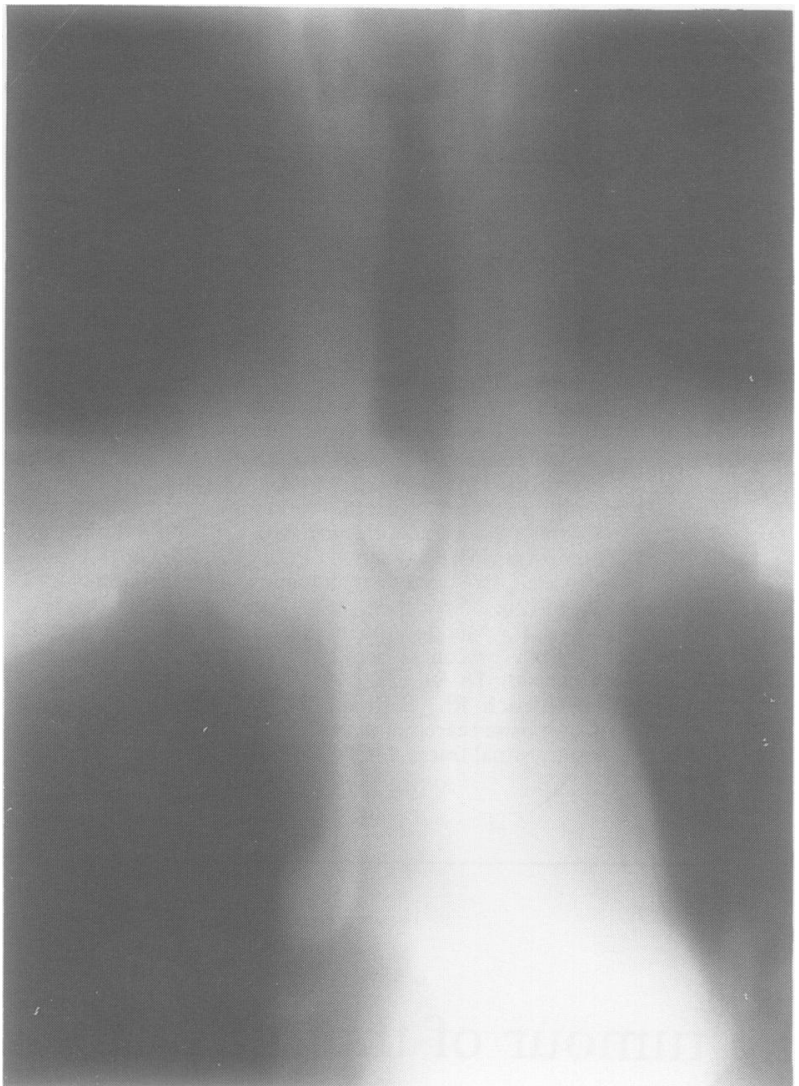

Figure 1 Tomograph of the chest taken on admission, showing a demarcated mass in mid-trachea paraffin wax. Sections $4 \mu \mathrm{m}$ thick were prepared for staining with haematoxylin and eosin and immunohistochemical stains.

Immunohistochemical staining was carried out using an avidin-biotin-peroxidase complex (ABC) method. The primary antibodies used were S-100 protein (Dako, Denmark; dilution 1 in 200), and anti-muscle actin antibody (Enzo Biochem Inc., New York; dilution 1 in 1500).

\section{Pathology}

MACROSCOPIC FINDINGS

A sessile, red, elastic hard, polypoid tumour measuring $2.2 \times 1.0 \times 1.0 \mathrm{~cm}$ arising from the wall of the right side of the trachea occupied almost the entire tracheal lumen. The tumour appeared to be covered by epithelium and mucus, and its surface was smooth but nodular. The cut surface of the tumour was firm, homogenous, and greyish-white.

MICROSCOPIC FINDINGS

The tumour arose from the submucosal tracheal gland, but its main body protruded into the tracheal lumen. It had not infiltrated into the tracheal cartilage (fig 2). The luminal surface of the tumour was covered by respiratory epithelium and partly metaplastic squamous epithelium.

The tumour consisted of cords and sheets of uniform epithelial cells. Mitosis was rare. Tumour cells were uniform and had an oval nucleus and clear cytoplasm with little atypia. There was scant interstitial tissue among the tumour nests and there was little presence of organoid structure (fig 3). Evidence of previous bleeding and scar tissue was visible in the tumour.

Immunohistochemical staining showed that some tumour cells stained for S-100 protein (fig 3; inset), and that most of the tumour cells were stained for smooth muscle actin.

Excised thyroid nodule was microscopically diagnosed as papillary carcinoma.

\section{Discussion}

Tumours of the trachea and large bronchi are classified according to the WHO Histological Typing of Lung Tumours. ${ }^{4}$ However, there are a few cases in which this is not readily applicable.

In our case, tumour cells were histologically uniformly round and had clear cytoplasm. They did not create an organoid structure and the tumour had scant connective stroma. The nuclei of the tumour cells were single with evenly dispersed chromatin. Mitosis was rare. The histological findings seemed to be identical with the monomorphic adenoma of the trachea of the WHO classification. However, immunohistochemical examination indicated that the tumour cells featured $S-100$ protein and smooth muscle actin, suggesting that the origin of this tumour was the myoepithelial cells of the tracheal gland.

In 1972 Donath and coworkers described eight cases of a clear cell neoplasm of salivary gland origin, ${ }^{1}$ which they termed epithelial 


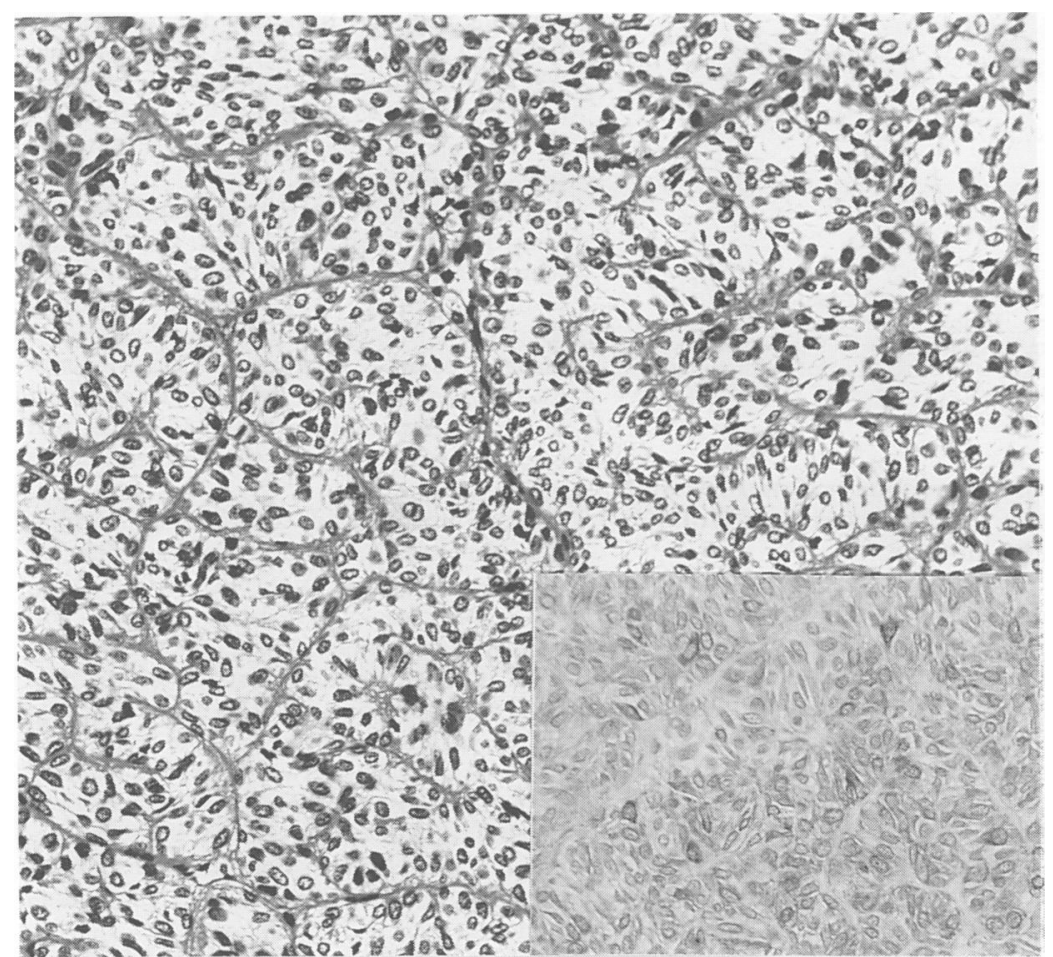

Figure 3 Epithelial cells devoid of mitosis. There was scant interstitial tissue in the nest of the tumour (haemotoxylin and eosin). Inset: some tumour cells were stained for $S-100$ protein
Differential diagnosis of epithelial myoepithelial carcinoma includes mucoepidermoid carcinoma, acinic cell carcinoma, sebaceous carcinoma, and metastatic renal cell carcinoma. The clear cells of mucoepidermoid carcinoma contain neutral epithelial mucin, and squamous differentiation is, by definition, a feature of this tumour. Sebaceous carcinoma is composed of "foamy" lipid rich clear cells. In acinic cell carcinoma characteristic secretory granules are evident with careful investigation.

Though our case had a monophasic structure, its cellular characteristics and immunohistochemical findings indicated that this was compatible with epithelial myoepithelial carcinoma. However, there was no local infiltration nor regional lymph node metastasis, and recurrence has not been detected for four years. Considering these points, we concluded that this tumour is an epithelial myoepithelial tumour rather than carcinoma.

As a final note, the papillary carcinoma of the thyroid found in this patient was thought to be a chance occurrence.

myoepithelial carcinoma of intercalated duct origin. They indicated that these tumours showed a characteristic biphasic dark and clear cell pattern. Luna and coworkers showed that in some cases of epithelial myoepithelial carcinoma the biphasic pattern is less apparent and that the histological appearances are dominated by solid groups of clear cells. ${ }^{5}$ Collina and coworkers also showed that the clear cells were stained for S-100 protein and smooth muscle actin. ${ }^{6}$ Furthermore, Morinaga and coworkers described a case of epithelial myoepithelial carcinoma of the parotid gland in an 8 year old child, and they mentioned the term epithelial myoepithelial carcinoma. ${ }^{7}$ They regarded monomorphic adenoma and epithelial myoepithelial carcinoma as confusing classifications.
1 Donath K, Seifelt G, Schmiz R. Zur Diagnose und Ultrastructur des Tubulalen Speichelgangcarcinoms: epithelial-myoepitheliales schaltstuckcarcinom. Virchows Arch (Pathol Anat) 1971;356:16-31.

2 WHO. Histological typing of lung tumours. 2nd edn. Geneva: WHO, 1981.

3 Seifelt G, Broucheriou C, Cardesa A, Eveson JW, WHO international histological classification of tumours. Tentainternational histological classification of tumours. TentaPath Res Pract 1990;186:555-81.

4 Thackray AC, Lucas RB. Tumors of the major salivary glands. In: Atlas of tumor pathology. 2nd series. Fascicle 10. Washington, DC: Armed Forces Institute of Pathology, 1974;62-3.

5 Luna MA, Batsakis JG, Ordonex NG, Mackey B, Tortoledo ME. Salivary gland adenocarcinomas: A clinicopathologic analysis of three distinctive types. Semin Diagnost Pathol 1987;4:117-35.

6 Collina G, Gale N, Visona A, Betts CM, Cenacchi V, Eusebi V. Epithelial-myoepithelial carcinoma of the parotid gland: A clinicopathologic and immunohistochemical study of seven cases. Tumori 1991;77:257-63.

7 Morinaga S, Hashimoto S, Tezuka F. Epithelial-myoepithelial carcinoma of the parotid gland in a child. Acta Pathol Ұpn 1992;42:358-63. 